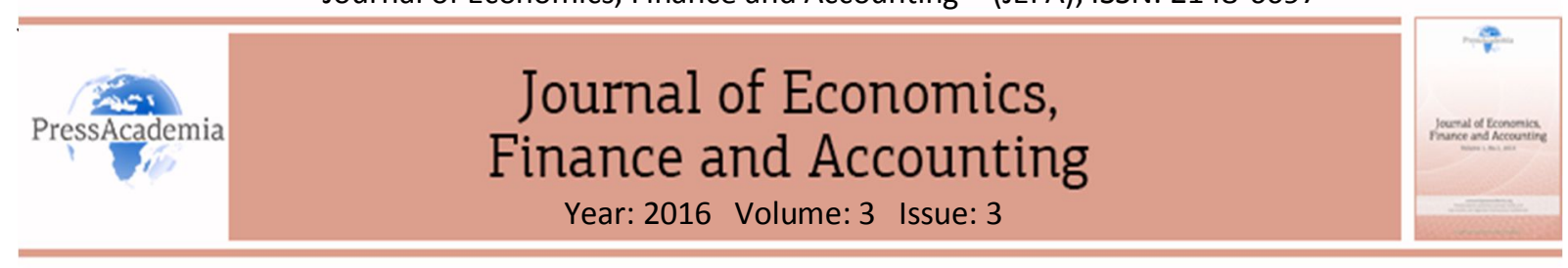

\title{
EMPIRICAL ANALYSIS OF INTERACTION BETWEEN PROMOTION EXPENDITURES AND TOURISM: THE CASE OF TURKEY*
}

\section{DOI: 10.17261/Pressacademia.2016321988}

Ceyhun Can Ozcan ${ }^{1}$, Gunay Ozcan²

${ }^{1}$ Necmettin Erbakan Üniversitesi. ceyhuncan5@hotmail.com

${ }^{2}$ Necmettin Erbakan Üniversitesi. gakel@konya.edu.tr

\begin{abstract}
The Turkish tourism sector is among the first places in international markets in terms of number of visiting tourists. But the same situation is not valid in terms of tourism revenue. At this point, tourism promotion becomes important for the Turkish economy. The Ministry of Culture and Tourism arranges promotional activities in different regions of the world to increase the number of tourists and revenue of tourism sector. But it is possible to interpret that tourism demand is not sufficient compare to potential of the country because of absence of effective and planned promotion policy. The aim of this study is to test interaction between tourism promotion expenditures, tourism revenue and number of tourists by employing recently developed Vector Autoregressive based Toda-Yamamoto and conventional Granger causality methods. In the study, annual data belonging to period between years 1990 and 2012 is used. Results of the empirical analyses give evidences about the relation between tourism promotion expenditures, tourism revenue and number of tourists. Findings obtained from both conventional Granger and Toda - Yamamoto causality tests imply that there is a causation linkage running from tourism promotion expenditures to number of tourists visiting Turkey. Results also indicate that there is no causal relationship between tourism promotion expenditures and tourism revenue.
\end{abstract}

Keywords: Tourism, tourism demand, promotion expenditure, tourism income JEL Classification: C22,L83,Z33

\section{TANITIM HARCAMALARI VE TURIZM iLIŞKISININ AMPIRIK BiR ANALIZi: TÜRKIYE ÖRNEĞi}

\section{ÖZET}

Uluslararası piyasalarda, turizm sektörü ile ilk sıralarda yer alan Türkiye ziyaretçi sayısı açısından elde ettiği başarıyı, turizm geliri açısından elde edememiştir. Bu noktada Türkiye'nin turizm tanıtımı oldukça önemli hale gelmektedir. Kültür ve Turizm Bakanlığı her yıl yurtdışında tanıtım faaliyetlerinde bulunmaktadır. Ancak etkin ve planlı bir tanııı politikası oluşturulamadığından yeterli turizm talebi yaratılamamaktadır. Bu çalışmanın amacı turizm tanıtım harcamaları ile elde edilen turizm geliri ve gelen turist sayısı arasındaki ilişkiyi son dönemlerde yaygın olarak kullanılmaya başlayan Toda-Yamamoto nedensellik testi ile VAR'a dayalı klasik Granger nedensellik testi yöntemleri ile test etmektedir. Çalışmada, 1990-2012 yılları arasındaki döneme ait veriler kullanıımışır. Analizde turizm tanııım harcamaları (TH), turizm geliri (TG), turist sayısı (TS) değişkenleri arasında bir ilişkinin olduğuna dair kanıtlar elde edilmiş̧tir. Zira elde edilen bulgular, turizm tanıtım harcamaları hem geleneksel Granger nedensellik testi hem de Toda-Yamamoto nedensellik sonuçlarına göre turist sayısının Granger nedenidir. Tanıtım harcamaları ve turizm geliri arasında bir ilişki bulunamamıştır.

*Çalışmanın özeti II. Avrasya Turizm Kongresi'nde sunulmuştur. 


\section{GíRiş}

Turizm sektörü, dünya ekonomisinde akış halinde olan ve birçok etkene bağlı gelişen bir gelir kaynağıdır. Özellikle 20. yüzyılın ikinci yarısından sonra yaşam kalitesi ve refah düzeyi artan ülkelerde turizm artık ön plana çıkmış olup insanlar kendi kültürleri dışındaki, farklı kültürleri incelemeye, tanımaya ve onlarla etkileşim kurmaya başlamışlardır. Güvenilir ve ihtiyaçlarını karşılayacak yeni yerler arayan insanlar yeni teknolojilerle birlikte dünyada gidebilecekleri yerleri keşfedip başka ülkeleri ziyaret etmektedirler. İnsanlar ekonomik, sosyal, kültürel, ekolojik ve teknolojik değişimlerin sonucunda ihtiyaçlarını turizm faaliyetlerine katılarak karşılamaya başlamışlardır. Ülke ekonomisine büyük bir katkı sağlamasından dolayı turizm faaliyetleri sosyal, kültürel, politik etkilerinden çok ekonomik etkileri ile çalışmalara konu olmuştur. Turizm ulusların gelirini arttıran, ülkelere döviz girdisi sağlayan, yatırımları arttıran, yeni istihdam olanakları yaratan, ödemeler bilançosu eşitliğini sağlayan, bölgesel ve ulusal ekonomik gelişmelere katkıda bulunmada rol oynayan önemli bir faktör haline gelmiştir. Turizmin bu ekonomik yönü gelişmekte olan ülkeler için kalkınmanın itici gücü olarak kabullenmesine yol açmıştır. Bu güçten yararlanmak isteyen ülkeler uluslararası pazarda turist potansiyeline erişmek için rekabet etmek zorundadırlar.

Dünya'da ve Türkiye'de önemli bir yere sahip olan turizm sektöründen beklenen yararların gerçekleşebilmesi için öncelikle etkin bir talebin yaratılması, yaratılan aktif talebin beklentilere cevap verebilecek arz kaynaklarının varlığına ve turistlerin ülkelerine memnun dönmelerinin sağlanmasına bağlıdır. Turizm talebini, yeterli satın alma gücüne ve boş zamana sahip olup belirli bir zaman diliminde farklı amaçlar doğrultusunda turistik mal ve hizmetlerden faydalanan ya da yararlanmak isteyen kişiler oluşturmaktadır (Olalı ve Timur, 1987, s.196). Söz konusu talebin yaratılması içinde etkili tanıtım ve imaj faaliyetlerine ihtiyaç duyulmaktadır (Çetinel, 2001, s.151). Yabancıların belli bir ülke ya da bölgeyi ziyaret etmek için kararlarını belirleyici nedenlerden birisi turizm şirketlerinin ve hükümetlerin tanıtım, reklam ve pazarlama faaliyetleridir.

Tanıtma, bir ülkenin kamuoyunda olumlu bir imaj yaratmak amacıyla çeşitli iletişim tekniklerinden yararlanarak açık, sürekli ve yoğun şekilde yürütülen bilgilendirme faaliyetleridir ( Hacıoğlu 1992, s. 125 ). Bir başka deyişle “ Ulusal, toplumsal, öznel veya nesnel bir imge yaratmak için halka ilişkiler ve enformasyon hizmetlerini sürdüren her türlü iletişim düzenlemeleridir" şeklinde de ifade edebiliriz ( Eralp, 1978, s.160-163). Turizmde tanıtım ise insanların ilgilerini bir ülkenin, bölgenin veya turistik istasyonun mal ve hizmetleri üzerine çekmek, bilgi vermek, hafızada bir imaj yaratmak suretiyle turistik mal ve hizmetleri satın almaya yöneltmek, bütün bunların sonucunda ekonomik kazanç sağlamak amacıyla yararlanılan teknikler bütünü olarak ifade etmek mümkündür (Oral, 1994'den aktaran Turanlı, 2003: 4). Bu doğrultuda turistik tanıtım ile dış tanıtım kavramlarını birbirinden ayırmak gerekmektedir. Bir ülkenin dış tanıtımı çok daha kapsamlı olup siyasal, ekonomik, kültürel ve turizm tanıtımını birlikte içinde barındıran bir kavramdır (Olalı, 1983, s. 10).

Tanıtım, turizmin gelişmesi, ülkeye yönelik talebin artması açısından hayati derecede önemlidir. Tanıtım sayesinde insanların dikkatini turistik mal ve hizmetlerin üzerine çekme, onlara bu mal ve hizmetlerin fiyatları, özellikleri, kaliteleri gibi konularda bilgi verme, telkinde bulunma ve bunun sonucunda da hedef kitle veya kitlelerin nezdinde olumlu bir imaj yaratma sansına sahip olunabilmektedir (Arslan, 2007, s. 4-5).

Son yıllarda yaşanan hızlı nüfus artışı, ekonomik kriz, iklim değişikliği, enerji ihtiyacı, açlık, fakirlik, göç, sosyal kaynaşma, ülkesel bütünlük, terör, güvenlik gibi sayıları giderek artan sorunlar uluslararası toplumu meşgul etmektedir. Bu sorunlara, küreselleşme olgusunun beraberinde getirdiği olumlu ve olumsuz gelişmeler sonucunda dünya, köklü bir değişim ve dönüşüm süreci içine girmiştir. Bu süreçte, farklı özellik ve birikimlere sahip bölgeler ile kıtalar arasındaki yolların kesiştiği kavşakta yer alan Türkiye, coğrafi konumunun yarattığı fırsatları değerlendirip, olumsuz etkileri kazanımlara dönüştürebilme potansiyeline sahiptir. Bu kazanımları elde edebilmenin bir yönü turizm tanıtım kampanyalarıyla turistleri çekebilmektir.

Türkiye'nin tanıtımı ile ilgilenen kuruluşların sayısı oldukça fazladır ve bunların faaliyetlerinin Türkiye'nin tanıtım uygulamaları olarak nitelendirilmesi mümkündür. Söz konusu kuruluşlar arasında en yetkili olan kurum Turizm Bakanlığı dır. Türkiye'nin yurt dışındaki imajının geliştirilmesi, Türkiye'nin uluslararası turizm pazarındaki payının artırılması, böylece hem döviz kazandıran hem de istihdam yaratan bir sektör olan turizmin, ülkenin sosyo ekonomik gelişimine olan katkılarının en üst düzeye çıkarılması, bakanlığın tanıtım faaliyetlerinin amacı olarak belirtilmiştir (Şahbaz, 2000). 
Bu çalışmada turizm tanııım harcamaları ile elde edilen turizm geliri ve gelen turist sayısı arasındaki ilişkiyi son dönemlerde yaygın olarak kullanılmaya başlayan VAR nedensellik ve Toda-Yamamoto nedensellik testi gibi ekonometrik yöntemlerle test etmektedir. Çalışmanın tasarımı şu şekildedir: birinci bölüm giriş, ikinci bölümde literatür taraması, üçüncü bölümde ekonometrik yöntem ve verilerin tasarımı, dördüncü bölümde ampirik bulgular ve son bölümde ise sonuç ve öneriler kısmına yer verilmektedir.

\section{LITERATÜR TARAMASI}

Türkiye'nin tanıtımına yönelik harcanan kaynakların, turizm talebine ve turizm gelirine olumlu etkisinin olup olmadığına dair ilk çalışma 1984-1999 yılları arasını kapsayacak şekilde Şahbaz (2000) tarafından gerçekleştirilmiştir. Şahbaz çalışmasında, sonuç olarak Türkiye'nin yurt dışında tanıtılması için gerçekleştirilen harcamalar ile Türkiye'nin turizm gelirleri ve Türkiye'ye gelen turist sayısı arasında olumlu yönde bir ilişki olduğu ortaya koymuştur.

Tanıtım harcamaları ve turizm talebi üzerine yapılan çalışmalara baktı̆ı̆ııda Arslan (2014), 2001-2012 yılları arasında tanııı harcamalarının dış turizm talebine ve turizm gelirine olan etkisinin ölçmüştür. Bu çalışmanın Korelasyon ve Regresyon analizleri yardımıyla ulaştığı ortak sonuç, dış turistik tanıtım harcamaları ile turizm talebi ve turizm geliri arasında pozitif yönlü ilişkinin olduğu ve bu anlamda tanıtım ile talep ve gelir arasında olumlu bir ilişki olduğu sonucunda tanıtmaya daha fazla kaynak ayrılmasıyla diğer bağımlı değişkenlerde iyileşmelerin olacağı belirtilmiştir.

Tuna ve Çatı (2007) ise çalışmalarında, 1990-2006 dönemindeki tanıtım harcaması ile turizm talebi ve turizm geliri arasındaki ilişkiyi araştırmışlardır. Sonuç olarak, tanıtım harcamaları ile turizm talebi ve turizm geliri arasında pozitif yönlü ilişkinin olduğu ortaya çıkmıştır.

F.G. Çetinel'in (2001) yaptığı çalışmada 1996-2000 yılları arasında yurtdışında hedef pazar ülkelerde yazılı ve görsel medyada yer alan tanııım faaliyetlerinin Türkiye'nin dış aktif turizm hareketine katılan turist sayısına etkisi ve medya araçlarının etkinliği ortaya konulmuştur.

Yurtdışında yapılan çalışmalara bakıldığında Divisekera ve Kulendran (2006), tanıtım harcamalarının turizm talebi üzerine etkilerini incelemiş, Avustralya’ya gelen turistlerden Japon turist talebinin tanıtım harcamalarına olumlu etkisi olduğu sonucuna varmıştır.

Diğer bir çalışma ise Deskins ve Seevers (2011), ABD eyaletlerinde hükümetin turizm tanıtım harcamalarının turizme etkisini araştırmışlardır. 1985-2003 yılları arasındaki dönemi ele alan çalışmada turizm tanıtım harcamalarının, eyaletlerin ekonomik büyümeleri ve eyaletin istihdamındaki etkileri araştırılmıştır. Elde edilen bulgular turizm tanıtım harcamalarındaki yükselmenin, turizm ve istihdam üzerindeki etkisinin turizm harcamalarına bağlı olduğu sonucunu göstermektedir. Ek bir turizm tanıtım harcaması, turizm ve istihdamdaki büyümeyi artırdığı sonucuna varmışlardır.

\section{VERI SETI VE METODOLOJi}

Bu çalışmada kullanılan veri seti T.C. Kültür ve Turizm Bakanlığı ve Dünya Bankası (WDI) veri tabanından temin edilmiştir. 1990-2012 dönemine ait yıllık serilerin kullanıldığı analizlerde tüm serilerin öncelikli olarak logaritmaları alınmıştır. Analizlerde E-Views 8.0 versiyonundaki ekonometrik paket programından yararlanılmışıı. Çalışmada kullanılacak olan ekonometrik modelin temel amacı, turist sayısı, turizm geliri ve turizm tanıım harcamaları arasındaki nedensellik ilişkisini saptamaktır. Modelin basit şekilde ifade edilmiş hali aşağıdaki gibidir. Değişkenlerin modeli etkileme yönünün pozitif (+) olması beklenmektedir.

$f=(T S, T H, T G)$

Bu kapsamda oluşturulan modele ilişkin değişkenler ve anlamları aşağıda açıklanmaktadır:

TS: Ülkeye Gelen Yabancı Turist Sayısını,

TH: Turistik Tanıtım Harcamaları Bütçesi(milyon TL)

TG: Turizm Gelirleri (milyar TL), ifade etmektedir. 


\subsection{Birim Kök Testleri}

Geleneksel Dickey-Fuller (DF) testleri sadece birinci dereceden bir AR (autoregressive) sürecini temel alarak süreci yürütürler (Dickey ve Fuller, 1981, s.1057-1072). Teste p gecikme uzunluğu olmak üzere $A R(p)$ modeli için; boş hipotezinde $\operatorname{ARIMA}(p, 1,0)$ otoregresif eşbütünleşik hareketli ortalama (autoregressive integrated moving average) sürecine karşılık alternatif hipotezde durağan $\operatorname{ARIMA}(p+1,0,0)$ süreci test edilir. Ancak hata teriminin beyaz gürültü özelliği gösterebilmesi diğer bir ifadeyle $y_{t}$ serisinin önemli gecikmelerinden birisi unutulursa hata teriminde otokorelasyona neden olunur ve modele daha yüksek dereceden AR kökü eklemek gerekebilir. DF testinde 1. dereceden otokorelasyon süreci alındığı için hata teriminin $\left(\varepsilon_{t}\right)$ beyaz gürültü özelliği gösterebilmesi amacıyla daha yüksek seviyede otokorelasyon sürecine sahip modellerin alınması gerekir (Kayhan vd., 2013, s.198).

$$
\begin{array}{ll}
\Delta y_{t}=\gamma y_{t-1}+\sum_{i=2}^{p} \beta_{i} \Delta y_{t-i+1}+\varepsilon_{t} & \\
\Delta y_{t}=c+\gamma y_{t-1}+\sum_{i=2}^{p} \beta_{i} \Delta y_{t-i+1}+\varepsilon_{t} & \\
\left.\Delta y_{t}=c+\gamma y_{t-1}+\delta_{2} t+\sum_{i=2}^{p} \beta_{i} \Delta y_{t-i+1}+\varepsilon_{t}\right) & \\
& \varepsilon_{\mathrm{t}} \sim \mathrm{WN}\left(0, \sigma^{2}\right) \\
&
\end{array}
$$

1 no'lu denklemdeki regresyon sabit terimsiz ve trend değişkeninin olmadığı modeli, 2'deki regresyon sadece sabit terimin dahil edildiği modeli, 3'deki regresyon sabit terim ve trend değişkeninin dahil edilen modeli ifade etmektedir. Test süreci $\gamma$ değişkeninin birden küçük olup olmaması üzerine kuruludur. Birim kök testi sonucunda boş hipotezin reddi diğer bir ifadeyle alternatif hipotezin kabul edilmesi $y_{t}$ serisinin birim kök taşımadığı ve durağan olduğu sonucuna ulaştırır. Serinin düzey değerinde durağan olması I(0), birinci farkında durağan olması I(1) ile ifade edilmektedir. Dickey-Fuller (1979) ADF testinin limit dağılımlarını türetmiş ancak MacKinnon $(1991,1996)$ sonlu örneklemler için kritik değerleri elde etmiştir.

\subsection{Toda-Yamamoto Nedensellik Testi}

Toda-Yamamoto (1995), VAR modeline dayanan ve değişkenlerin durağan olmadıkları durumda da düzey değerlerinin modele dâhil edildiği VAR modelinin tahmin edilmesine imkân vermekte ve standart Wald testinin uygulanmasını önermektedir. Ayrıca, serinin $k$ serbestlik derecesi ile asimptotik $\chi^{2}$ dağılımına sahip olduğu da ifade edilmektedir.

Bu bağlamda $y_{t}$ dizisi 4 numaralı denklemdeki doğrusal fonksiyon ile şu şekilde ifade edilmektedir:

$y_{t}=\beta_{0}+\beta_{1} t+\cdots+\beta_{q} t^{q}+\eta_{t}$

$\operatorname{VAR}\left(k+d_{\text {max }}\right)$ modelinde $k$, gecikme uzunluğunu ifade etmekte ve $d_{\text {max }}$ ise maksimum entegrasyon derecesini ifade etmektedir. Buna göre, $\eta_{t}$ VAR dizisi 5 numaralı denklemdeki gibi ifade edilmektedir:

$\eta_{t}=J_{1} \eta_{t-1}+\cdots+J_{k} \eta_{t-k}+\varepsilon_{t}$

Burada, $t=-k+1, \ldots, 0$ olmak üzere, $\eta_{t} ; \eta_{-k+1}, \ldots, \eta_{0}$ şeklini almaktadır.

Böylece,

$\eta_{t}=y_{t}-\beta_{0}-\beta_{1} t-\cdots-\beta_{q} t^{q}$

eşitliği elde edilmiş olur ve bu eşitliği 6 numaralı denklemdeki yerine yazacak olursak: 
$y_{t}=\gamma_{0}+\gamma_{1} t+\cdots+\gamma_{q} t^{q}+J_{1} y_{t-1}+\cdots+J_{k} y_{t-k}+\varepsilon_{t}$

eşitliğini elde etmiş oluruz.

Burada $\gamma_{i}(i=0, \ldots, q) ; \beta_{i}(i=0, \ldots, q)$ ve $J_{h}(h=1, \ldots, k)^{\prime}$ nin fonksiyonlarıdır. 7 ve 8 numaralı denklemlerdeki $q=1$ ve $d=1$ olarak kabul eder ve 9 numaralı denklemi yeniden yazarsak:

$y_{t}=\gamma_{0}+\gamma_{1} t+J_{1} y_{t-1}+\cdots+J_{k} y_{t-k}+\varepsilon_{t}$

eşitliği elde edilmiş olur. Toda-Yamamoto (1995), VAR sürecinin durağanlığı ile değil, 8. numaralı denklemdeki $y^{\prime}$ nin gecikme uzunluğu ile ilgilenmektedir (Toda-Yamamoto, 1995: 227-228).

\section{BULGULAR}

Değişkenlere VAR'a dayalı Granger nedensellik ve Toda-Yamamoto nedensellik yöntemi uygulanmadan önce birim kök sorunundan arındırılması gerekmektedir. Bu amaçla seri mevsimsellikten ayrıştırıldıktan sonra Dickey ve Fuller (1979, 1981, ADF) tarafından geliştirilen birim kök testi yapıımıştır.

Tablo 1: Birim Kök Test Sonuçları

\begin{tabular}{|c|c|c|c|c|c|}
\hline \multirow{2}{*}{\multicolumn{2}{|c|}{ Değişkenler }} & \multicolumn{2}{|c|}{$\begin{array}{l}\text { ADF- } p \text { istatistiği } \\
\text { (Düzey) }\end{array}$} & \multicolumn{2}{|c|}{$\begin{array}{c}\text { ADF - } p \text { istatistiği } \\
\text { (Birinci Fark) }\end{array}$} \\
\hline & & Trendsiz & Trendli & Trendsiz & Trendli \\
\hline \multicolumn{2}{|l|}{ LTS } & 0.8932 & 0.1590 & $0.0001 * * *$ & $0.0006 * * *$ \\
\hline \multicolumn{2}{|l|}{ LTG } & 0.7032 & 0.6786 & $0.0099 * * *$ & $0.0372 * *$ \\
\hline \multicolumn{2}{|l|}{$L T H$} & 0.3120 & 0.1291 & $0.0001 * * * *$ & $0.0003 * * *$ \\
\hline \multirow{3}{*}{ Anlamlılık Düzeyi } & $\% 1$ & -3.769 & -4.440 & -3.788 & -4.467 \\
\hline & $\% 5$ & -3.004 & -3.632 & -3.012 & -3.644 \\
\hline & $\% 10$ & -2.642 & -3.254 & -2.646 & -3.261 \\
\hline
\end{tabular}

Notlar: *.* ve *** değerleri sırasıyla \%1. \%5 ve \%10 anlam seviyelerinde serilerin durağanlıklarını göstermektedir. ADF Testi için: * değeri SIC kriterine göre seçilen gecikme uzunluklarını ve gecikme uzunluklarının sıfır olması durumunda Dickey-Fuller test sonuçlarını göstermektedir.

Sonuçların yer aldığı Tablo 1'de değişkenlerin düzey değerlerinde birim kök taşıdığı, bu yüzden birinci farklarını alarak analize devam edilmesi gerektiği görülmektedir.

Tablo 2'de Korelasyon katsayısı sonuçlarına ilişkin bulgular yer almaktadır. Elde edilen bulgular Turizm Geliri (TG), Turist Sayısı (TS) ve Turizm harcamaları (TH) arasındaki ilişkilerin güçlü olduğunu göstermektedir.

Tablo 2: Korelasyon Katsayısı Sonuçları

\begin{tabular}{|l|c|c|c|}
\hline & LTS & LTG & LTH \\
\hline LTS & 1 & -0.5994 & 0.9061 \\
\hline LTG & -0.5994 & 1 & -0.3847 \\
\hline LTH & 0.9061 & -0.3847 & 1 \\
\hline
\end{tabular}

Öte yandan VAR'a dayalı Granger nedensellik yaklaşımında gecikme sayısı önemlidir. Tahmin edilecek VAR modeline geçilmeden önce, model için uygun gecikme uzunluğunun belirlenmesi gerekmektedir.

Gecikme seviyesi araştırılan konunun niteliğine ve araştırmacının isteğine göre keyfi belirlenebileceği gibi tahminlerin güvenilirliği açısından bir kısım seçim kriterlerine başvurularak da belirlenebilmektedir. Son Tahmin Hatası (FPE), Akaike Bilgi Kriteri (AIC), Hannan Quinn (HQ) ve Schwartz (SC) kriterleri gecikme seviyesinin tespitinde kullanılan kriterler arasında yer almaktadır (Bozkurt, 2007, s.103-105; Çoban ve Özcan, 2013, s. 252). Çalışmada gecikme uzunluğu, VAR modeli için SC, LR, FPE ve HQ kriterleri 1 gecikme uzunluğunu vermektedir. Optimal gecikme seviyesi için dört kriterin de 1 gecikmeye işaret etmesi nedeniyle analizde gecikme seviyesinin 1 olmasına karar verilmiştir. 


\subsection{VAR-Granger Nedensellik Testi Sonuçları}

Optimal gecikme seviyesi 1 olarak belirlenmesinden bir sonraki aşama olan VAR'a dayalı Granger nedensellik analizine geçilmiştir. Elde edilen sonuçlar Tablo 3'de sunulmaktadır.

Tablo 3: VAR-Granger Nedensellik Sonuçları

\begin{tabular}{|c|c|c|}
\hline Değişkenler & & \\
\hline $\begin{array}{l}\text { MODEL I } \\
\text { (Bağımlı Değişken= TS) }\end{array}$ & Ki-Kare & Olasılık \\
\hline$T H=>T S$ & 5.571634 & $0.0183^{* *}$ \\
\hline$T G=>T S$ & 0.267961 & 0.6047 \\
\hline \multicolumn{3}{|l|}{$\begin{array}{l}\text { MODEL II } \\
\text { (Bağımlı Değiş̧ken= } T H \text { ) }\end{array}$} \\
\hline$T S=>T H$ & 3.092140 & $0.0787^{*}$ \\
\hline$T G=>T H$ & 1.239729 & 0.2655 \\
\hline \multicolumn{3}{|l|}{$\begin{array}{l}\text { MODEL III } \\
\text { (Bağımlı Değişken= TG) }\end{array}$} \\
\hline$T S=>T G$ & 1.315738 & 0.2514 \\
\hline$T H=>T G$ & 0.122875 & 0.7259 \\
\hline
\end{tabular}

*,** ve $* * *$ değerleri sırasıyla \%1, \%5 ve \%10 anlam seviyelerinde serilerin durağanlıklarını göstermektedir.

Tablo 3'de görüldüğü üzere nedenselliğin yönü açısından modeller değerlendirildiğinde Model I'de "Turist Harcamaları, turist sayısının Granger nedenidir" sonucu \%5 anlamlılık seviyesinde kabul edilmiştir. Model II'de ise "Turist Sayısı Turizm harcamalarının Granger nedenidir" hipotezine baktığımızda ise \%10 anlamlılık seviyesinde kabul edilmektedir. Dolayısıyla Turizm tanıtım harcamaları ile turist sayısı arasında çift yönlü bir ilişki vardır (LREX<=> LTS). MODELDE II ve Model III ise elde edilen bulguların anlamlı olmadığı sonucuna varılmaktadır.

\subsection{Toda-Yamamoto Nedensellik Sonuçları}

Granger Nedensellik Testi'nden elde edilen sonuçların ardından çalışmada elde edilen sonuçları güçlendirmek amacıyla ek olarak ikinci adımda Toda-Yamamoto nedensellik testi de kurulan modellerde çalıştırılmıştır. Seriler orjinal değerleri ile $P+d_{\max }=3+1=4$ gecikme değerleri için tahmin edilmiştir. $M$ Wald (Modified Wald) sınaması ise $p=3$ gecikme değeri için test çalıştırılmıştır. Elde edilen sonuçlar Tablo 4'de sunulmaktadır.

Tablo 4: Toda-Yamamoto Nedensellik Sonuçları

\begin{tabular}{|l|c|c|}
\hline Değişkenler & & \\
\hline MODEL I (Bağımlı Değişken= TS) & F ístatistik Değeri & Olasılık \\
\hline TH=>TS & 3.171568 & $0.0749 *$ \\
\hline$T G=>T S$ & 0.624327 & 0.4294 \\
\hline MODEL II (Bağımlı Değişken= TH) & & 0.8850 \\
\hline$T S=>T H$ & 0.020920 & 0.9038 \\
\hline$T G=>T H$ & 0.014594 & 0.9054 \\
\hline MODEL III (Bağımlı Değişken= TG) & & 0.4965 \\
\hline$T S=>T G$ & 0.014130 & \\
\hline$T H=>T G$ & 0.462437 & \\
\hline
\end{tabular}

Not: Oklar ilişkinin yönünü göstermektedir.

Toda-Yamamoto nedensellik testinden elde edilen sonuçlar incelendiğinde Granger nedensellik testi sonuçlarının büyük ölçüde örtüştüğü gözlenmektedir. Turizm harcamaları turist sayısının \%10 anlamlılık düzeyinde nedenidir. Ancak turist sayısı ve turizm gelirleri turizm harcamasının nedeni değildir. 


\section{SONUÇ}

Bu çalışmada, Türkiye'de turist sayısı, turizm tanıtım harcamaları ve turizm geliri arasındaki ilişki Granger Nedensellik Testi ve Toda-Yamamoto Yaklaşımları kullanılarak analiz edilmiştir. Elde edilen bulgular kurulan modellerin doğruluğunu kanıtlamaktadır. Granger nedensellik sonuçlarına göre turist sayısı ve turizm tanıtım harcamaları arasında çift yönlü bir nedensellik mevcutken; Turizm geliri ile herhangi bir nedensellik ilişkisi bulunmamaktadır. Toda-Yamamoto testi sonuçlarına göre turist sayısı ile yine turizm tanıtım harcamaları arasında bir nedensellik olduğu sonucuna varılmaktadır. Diğer değişkenler arasında ise herhangi bir nedensellik ilişkisi kurulamamıştır. Teorik olarak da aslında beklenti turizm tanıtım harcamaların kamunun tek taraflı kararlılı̆ına bağlı bir parasal büyüklüktür. Bu yüzden de turizm gelirlerinden etkilenmemesi teorik olarak da beklenen bir olgudur. Öte yandan turist sayısının turizm tanıtım harcamalarını uzun dönemde motive etmesi beklenebilir ve elde edilen bulgular bunu destekler niteliktedir.

Son olarak sonraki araştırmalar için yol gösterici olması açışından iki öneri sunulabilir: İlk olarak bu çalışma sadece Türkiye turizmi ve tanıtım harcamaları arasındaki ilişki üzerine yoğunlaşmaktadır. Bunun dışında farklı değişkenlerde modele dahil edilerek araştırmanının kapsamı genişletilebilir. Literatür taraması kısmı bu anlamda yol gösterici niteliktedir. İkinci olarak, çalışmada sadece nedensellik ilişkisi ampirik olarak test edilmiş olup eşbütünleşme tahminine yer verilmemiştir. Bu bulgular ışığında farklı ekonometrik testler de yapılabilir.

\section{KAYNAKLAR}

Arslan, A, (2014). Türkiye'nin Dış Turistik Tanıtımının Turizm Talebine Etkisi: 2001-2012 Dönemi, Çankırı Karatekin Üniversitesi Sosyal Bilimler Enstitüsü Dergisi, 5(1),181-192.

Avcıkurt, C. (2005), “Turizmde Tanıtma ve Satış Geliştirme”, Değişim Yayınları, İstanbul, 2005.

Bozkurt, H. (2007) "Zaman Serileri Analizi”, Ekin Kitabevi, Bursa, 104s.

Çatı, K.,Tuna, H. (2007). Türkiye'nin Tanıtım Harcamaları ile Turizm Geliri Arasındaki iliş̧kinin Belirlenmesine Yönelik Bir Araştırma, Abant İzzet Baysal Üniversitesi, Sosyal Bilimler Enstitüsü Dergisi (2): 13-33.

Çetinel, F.G. (2001). Turizmde Tanıtım ve Reklam Faaliyetlerinin Önemi, Anatolia: Turizm Araştırmaları Dergisi (2), 12, 151-161.

Çoban, O. ve Özcan, C. C. (2013). “Türkiye'de Turizm Gelirleri-Ekonomik Büyüme Illişkisi: Nedensellik Analizi (1963-2010)”, Eskişehir Osmangazi Üniversitesi iïB Dergisi, 8(1), 243-261.

Deskins, J. Seevers, M. T., (2011). Are State Expenditures to Promote Tourism Effective? Journal of Travel Research 50(2) 154-170.

Hacıoğlu, N. (1992). Dış Tanıtım ve Örgütleme Modeli, Turizm Yıllığı, Kalkınma Bankası Yayını, Ankara.

Harris, R. ve Sollis, R. (2003) “Applied Time Series Modelling and Forecasting”, www.unibayreuth.de/departments/rw/lehrstuehle/vwl1, (07.02.2015).

Karasu, T. (1990). Turizmde Tanıtma Üzerine, Anatolia: Turizm Araştırmaları Dergisi (1): 31-34.

Kayhan, S., Bayat, T. ve Koçyiğit, A. (2013). Enflasyon Hedeflemesi Rejiminde Öğrenme Süreci ve Asimetri: Markov Switching Ya klaşımı, Eskişehir Osmangazi Üniversitesi IiBF Dergisi, Nisan 2013, 8(1),191-212.

Modellemesi, İstanbul Ticaret Üniversitesi Dergisi (3), 1-13.

Olalı, H.,(1983). Dış Tanıtım ve Turizm , Türkiye İş Bankası Kültür Yayınları, Ankara.

Olalı, H., ve Timur, A. (1987). Turizm Ekonomisi, Ofis Matbaacılık, İzmir.

Rızaoğlu, Bahattin: “Turizmde Tanıtma”, Detay Yayıncılık, Ankara, 2004.

Şahbaz, P. (2000). Türkiye'nin Tanıtım Harcamalarının Dış Turizm Talebine Etkileri, Dokuz Eylül Üniversitesi, Sosyal Bilimler Enstitüsü Dergisi (2), 3, 121-150.

TCKTB (Türkiye Cumhuriyeti Kültür ve Turizm Bakanlığı) (2014) http://www.ktbyatirimisletmeler.gov.tr/belge/1-38683/turizmistatistikleri.html, (Erişim: 15.11.2011).

TCMB (Türkiye Cumhuriyet Merkez Bankası) (2012) http://evds.tcmb.gov.tr/cbt.html, (01.02.2015).

Toda, H. Y. \& Yamamoto, T. (1995) "Statistical inference in vector autoregressions with possibly integrated processes", Journal of Econometrics, 66(1), 225-250. 
Toda, Hiro Y. ve Yamamoto, T. (1995) "Statistical Inference in Vector Autoregressions with Possibly Integrated Processes", Journal of Econometrics,66, 225-250.

Turanlı, M., Güneren, E. (2003). Turizm Sektöründe Talep Tahmin

TÜiK (Türkiye İstatistik Kurumu) (2015) Web: http://www.tuik.gov.tr/UstMenu.do?metod=temelist, Erişim Tarihi: 15. 08.2015. 